\title{
The Influence of Student Personality and Teacher-student Interactions on Teacher-student Relationship Quality
}

\author{
Tengteng Tan, Naiyi Wang \\ Institute of Educational Psychology and School Counseling, Faculty of Education, Beijing Normal University, Beijing, P.R.China \\ wangnaiyi@bnu.edu.cn
}

\begin{abstract}
Teacher-student relationship is one of the basic interpersonal relationships of students in school environment, and is important for students' development. Understanding the mechanism underlying the formation of high quality teacher-student relationships has always been a key concern in the field of psychology. This study examined the direct and indirect influences of student personality and teacher-student interaction on teacher-student relationship quality by building up a path model of teacher-student relationship quality. Main results included: (1) student's cautiousness positively predicts teacher-student relationship quality; (2) different dimensions of student personality directly contribute to teacher-student interactions; (3) teacher proximity and student affiliation positively predict teacher-student relationship quality; (4) teacher proximity positively predicts student control; (5) the hypothesis that teacher-student interaction acts as a mediator between student personality and teacher-student relationship quality was not supported by the path model. Finally, implications for educational practices were discussed.

Index Terms - teacher-student relationship quality, student personality, teacher-student interaction, path analyses
\end{abstract}

\section{Introduction}

Teacher-student relationship is one of the most basic interpersonal relationships at school. A stable cognitive, behavioral and emotional connection is gradually built up between students and teachers during their long-term interactions. It has been found that positive relationships with teachers would promote students' development by many studies (e.g., [1]). On the contrary, negative relationships with teachers would impede students' development (e.g., [2]).

Adolescence is the key transitional period from childhood to adulthood, during which many dramatic and rapid developing changes would happen, such as promotion of self-consciousness, formation of self-concept as well as imbalance of psychological development. Meanwhile, higher requirements for teenagers' behavioral regulation, emotional adjustment and social skills are put forward by school and society [3]. Consequently, emotional, behavioral and various study-related hardships could be experienced during this important developing period [4]. The quality of teacherstudent relationship, one of the most basic interpersonal relationships for students, is highly related to students' development as teachers are the very adults who get most close contacts with students at school. Previous studies have proved that teacher-student relationship can be an indicator of students' academic achievement in both junior and senior middle school. With good teacher-student relationship, students are more likely to outperform others at school [5], and display more pro-social behaviors, greater responsibility, stronger sense of school belonging and higher level of mental health (e.g., [6]).

Previous studies on teacher-student relationship mainly focused on teachers. Studies from students' perspective are scarce. Further, the few studies focused on students only considered single characteristic of students such as shyness and effortful control, while rarely take students' personality as a whole. What's more, the existing studies seldom discussed the potential mediating role of teacher-student interaction between teachers or students' characteristics and teacherstudent relationship. For the above reasons, this research explored the direct and indirect effects of middle school students' personality and teacher-student interaction on teacher-student relationship quality by means of path analyses.

Our research hypotheses are as follow: (1) student personality contributes directly to teacher-student relationship quality; (2) student personality contributes directly to teacherand student-initiated interactions; (3) teacher- and studentinitiated interactions contribute directly to teacher-student relationship quality; (4) teacher- and student-initiated interactions contribute to each other; (5) teacher-student interaction acts as a mediator between student personality and teacher-student relationship quality.

\section{II . Method}

\section{A. Participants}

Participants were recruited from five middle schools in Beijing. Three to five classes were randomly selected from each grade. In total 27 classes were selected from grade 7 to grade 12. Classes with head teacher who had been in charge of the class less than three months were excluded. About 20 students were randomly selected from each class. In total 538 students and 27 head teachers participated in the study. Participants with incomplete questionnaires and extreme data were eliminated from analyses. The final sample comprised of 487 students and 25 head teachers.

\section{B. Measures}

1) Personality Questionnaire for Middle School Students: Student personality was measured using the Five-factor Personality Questionnaire for Middle School Students [7]. The questionnaire includes 50 items. The five personality dimensions are: extraversion, agreeableness, cautiousness, openness and emotionality.

2) Questionnaire on Teacher Interaction (QTI): The QTI was used to measure teacher-initiated interaction [8]. The 
questionnaire includes 64 items and eight sub-scales. The model consists of two dimensions: influence and proximity.

3) Student-Teacher Relationship Scale (STRS): The scale was originally designed by Pianta (1994). The revised version [9] consists of 28 items, measuring three dimensions of student-teacher relationship: conflict, closeness and reactivity. High score in each dimension represents low conflict, high closeness and high reactivity respectively.

4) Student's Interpersonal Behavior (micro-scale): Student-initiated interaction was rated by teachers with two six-point micro-scales that were developed by Thijs [10]. The two dimensions of students-initiated interaction are control and affiliation.

\section{Procedure and Data analyses}

Students completed the Five-factor Personality Questionnaire for Middle School Students and the QTI. Teachers completed the STRS and rated student-initiated interaction. Excel2007, SPSS17.0 and AMOS7.0 were used for data processing and analyses.

\section{Results}

\section{A. Regression analyses}

The effects of student personality on teacher-student relationship quality, teacher- and student-initiated interaction were tested using multiple regression analyses (Enter method). The results showed that student personality significantly predicts all three dependent variables (Table 1, $2 \& 3$ ).

TABLE 1 Regression analyses for the prediction of teacher-student relationship quality from students' personality

\begin{tabular}{|c|c|c|c|c|c|c|}
\hline $\mathrm{DV}$ & $\mathrm{PV}$ & $\mathrm{R}$ & $\mathrm{R}_{\text {adj }}^{2}$ & $\mathrm{~F}$ & $\beta$ & $t$ \\
\hline \multirow{5}{*}{$\mathrm{TSR}$} & $\mathrm{Ex}$ & 0.222 & 0.039 & $4.965^{* * *}$ & 0.121 & 1.424 \\
\cline { 2 - 6 } & $\mathrm{Ag}$ & & & & 0.183 & 1.273 \\
\cline { 2 - 6 } & $\mathrm{Ca}$ & & & & 0.246 & $2.651^{* *}$ \\
\cline { 2 - 6 } & $\mathrm{Op}$ & & & & -0.141 & -1.428 \\
\cline { 2 - 6 } & $\mathrm{Em}$ & & & & -0.053 & -0.882 \\
\hline
\end{tabular}

Note: $* * * p<.001, * * p<.01, * p<.05$. TSR=Teacher-student relationship quality; $\mathrm{DV}=$ Dependent variable; $\mathrm{PV}=$ Predictor variable; $\mathrm{Ex}=$ Extraversion; $\mathrm{Ag}=$ Agreeableness; $\mathrm{Ca}=$ Cautiousness; $\mathrm{Op}=$ Openness; $\mathrm{Em}=$ Emotionality .

TABLE 2 Regression analyses for the prediction of teacher-initiated interaction from student's personality

\begin{tabular}{|c|c|c|c|c|c|c|}
\hline $\mathrm{DV}$ & $\mathrm{PV}$ & $\mathrm{R}$ & $\mathrm{R}_{\text {adj }}^{2}$ & $\mathrm{~F}$ & $\beta$ & $t$ \\
\hline \multirow{4}{*}{ Influence } & $\mathrm{Ex}$ & 0.255 & 0.055 & $6.688^{* * *}$ & 0.268 & $2.467^{*}$ \\
\cline { 2 - 7 } & $\mathrm{Ag}$ & & & & 0.478 & $2.593^{*}$ \\
\cline { 2 - 7 } & $\mathrm{Ca}$ & & & & 0.028 & 0.235 \\
\cline { 2 - 7 } & $\mathrm{Op}$ & & & & -0.138 & -1.088 \\
\cline { 2 - 7 } & $\mathrm{Em}$ & & & & -0.151 & -1.954 \\
\hline \multirow{4}{*}{$\begin{array}{c}\text { Proximit } \\
\mathrm{y}\end{array}$} & $\mathrm{Ex}$ & 0.395 & 0.147 & $17.804 * * *$ & 0.320 & 1.386 \\
\cline { 2 - 7 } & $\mathrm{Ag}$ & & & & 2.024 & $5.174^{* * *}$ \\
\cline { 2 - 7 } & $\mathrm{Ca}$ & & & & 0.498 & $1.970^{*}$ \\
\cline { 2 - 7 } & $\mathrm{Op}$ & & & & -0.501 & -1.866 \\
\cline { 2 - 7 } & $\mathrm{Em}$ & & & & -0.530 & $-3.234^{* *}$ \\
\hline
\end{tabular}

Specifically, the results indicated that student's cautiousness positively predicts teacher-student relationship quality (Table 1). Students' extraversion and agreeableness positively predict teacher influence; students' agreeableness and cautiousness positively predict teacher proximity; students' emotionality negatively predicts teacher proximity (Table 2). Students' extraversion positively predicts student control, students' openness and emotionality negatively predicts student control; students' extraversion and agreeableness positively predicts student affiliation; students' openness and emotionality negatively predict student affiliation (Table 3).

TABLE 3 Regression analyses for the prediction of student-initiated interaction from student's personality

\begin{tabular}{|c|c|c|c|c|c|c|}
\hline DV & $\mathrm{PV}$ & $\mathrm{R}$ & $\mathrm{R}_{\text {adj }}^{2}$ & $\mathrm{~F}$ & $\beta$ & $t$ \\
\hline \multirow{5}{*}{ Control } & $\mathrm{Ex}$ & 0.203 & 0.031 & $4.155^{* *}$ & 0.169 & $2.042^{*}$ \\
\cline { 2 - 7 } & $\mathrm{Ag}$ & & & & 0.148 & 1.053 \\
\cline { 2 - 7 } & $\mathrm{Ca}$ & & & & 0.105 & 1.152 \\
\cline { 2 - 7 } & $\mathrm{Op}$ & & & & -0.261 & $-2.708^{* *}$ \\
\cline { 2 - 7 } & $\mathrm{Em}$ & & & & -0.160 & $-2.713^{* *}$ \\
\hline \multirow{5}{*}{ Affiliation } & $\mathrm{Ex}$ & 0.275 & 0.066 & $7.874^{* * *}$ & 0.263 & $3.308^{* *}$ \\
\cline { 2 - 7 } & $\mathrm{Ag}$ & & & & 0.334 & $2.484^{*}$ \\
\cline { 2 - 7 } & $\mathrm{Ca}$ & & & & 0.094 & 1.080 \\
\cline { 2 - 7 } & $\mathrm{Op}$ & & & & -0.283 & $-3.066^{* *}$ \\
\cline { 2 - 7 } & $\mathrm{Em}$ & & & & -0.119 & $-2.103^{*}$ \\
\hline
\end{tabular}

The influences of teacher- and student-initiated interaction on teacher-student relationship quality were tested using multiple regression analyses (Enter method). The results indicated that both significantly predict teacher-student relationship quality (Table 4, 5). Specifically, teacher proximity (Table 4) and student affiliation (Table 5) positively predict teacher-student relationship quality.

TABLE 4 Regression analyses for the prediction of teacher-student relationship quality from teacher-initiated interaction

\begin{tabular}{|c|c|c|c|c|c|c|}
\hline DV & PV & $\mathrm{R}$ & $\mathrm{R}_{\text {adj }}^{2}$ & $\mathrm{~F}$ & $\beta$ & $\mathrm{T}$ \\
\hline \multirow{2}{*}{ TSR } & Influence & 0.389 & 0.148 & $43.227 * * *$ & -0.044 & -1.291 \\
\cline { 2 - 7 } & Proximity & & & & 0.139 & $9.180 * * *$ \\
\hline
\end{tabular}

TABLE 5 Regression analyses for the prediction of teacher-student relationship quality from student-initiated interaction

\begin{tabular}{|c|c|c|c|c|c|c|}
\hline DV & PV & $\mathrm{R}$ & $\mathrm{R}_{\text {adj }}^{2}$ & $\mathrm{~F}$ & $\beta$ & $\mathrm{t}$ \\
\hline \multirow{2}{*}{ TSR } & Control & 0.537 & 0.285 & $98.033 * * *$ & 0.028 & 0.621 \\
\cline { 2 - 7 } & Affiliation & & & & 0.550 & $11.918 * * *$ \\
\hline
\end{tabular}

The influences of teacher- and student-initiated interaction on each other were tested using multiple regression analyses (Enter method). The results showed that both significantly predict each other (Table 6, 7). Specifically, teacher proximity positively predicts student control and affiliation (Table 6); student affiliation positively predicts teacher proximity (Table 7).

TABLE 6 Regression analyses for the prediction of student-initiated interaction from teacher-initiated interaction

\begin{tabular}{|c|c|c|c|c|c|c|}
\hline $\mathrm{DV}$ & $\mathrm{PV}$ & $\mathrm{R}$ & $\mathrm{R}_{\text {adj }}^{2}$ & $\mathrm{~F}$ & $\beta$ & $\mathrm{t}$ \\
\hline \multirow{2}{*}{ Control } & Influence & 0.229 & 0.048 & $13.364 * * *$ & 0.053 & 1.507 \\
\cline { 2 - 7 } & Proximity & & & & 0.067 & $4.283 * * *$ \\
\hline \multirow{2}{*}{ Affiliation } & Influence & 0.368 & 0.132 & $37.868 * * *$ & 0.021 & 0.642 \\
\cline { 2 - 7 } & Proximity & & & & 0.118 & $8.105 * * *$ \\
\hline
\end{tabular}


Table 7 Regression analyses for the prediction of teacher-initiated interaction from student-initiated interaction

\begin{tabular}{|c|c|c|c|c|c|c|}
\hline $\mathrm{DV}$ & $\mathrm{PV}$ & $\mathrm{R}$ & $\mathrm{R}_{\text {adj }}^{2}$ & $\mathrm{~F}$ & $\beta$ & $\mathrm{t}$ \\
\hline \multirow{2}{*}{ Influence } & Control & 0.152 & 0.019 & $5.730^{* *}$ & 0.109 & 1.605 \\
\cline { 2 - 7 } & Affiliation & & & & 0.128 & 1.823 \\
\hline \multirow{2}{*}{ Proximity } & Control & 0.370 & 0.133 & $38.319^{* * *}$ & 0.157 & 1.092 \\
\cline { 2 - 7 } & Affiliation & & & & 1.037 & $7.056^{* * *}$ \\
\hline
\end{tabular}

\section{B. Path model for teacher-student relationship quality}

Path analyses, using structural equation models, were conducted to examine the direct effects and indirect effects among variables based on the hypothesis that student personality contributes to teacher-student relationship quality through teacher-student interaction. According to the statistic methods for testing mediating effect [11], only when the regression coefficients among three variables are all significant, could the mediating effect be further estimated. Therefore, paths did not reach significant level in the multiple regression analyses were removed from the prediction model of teacher-student relationship quality before parameters were estimated. The model-fit testing results showed the effectiveness of the hypothesis model in integrating data collected (Table 8).

TABLE 8 Fitting indices of the prediction model for teacher-student relationship quality

\begin{tabular}{|c|c|c|c|c|c|c|c|}
\hline Fitting index & $\mathrm{x} 2$ & $\mathrm{df}$ & $\mathrm{x} 2 / \mathrm{df}$ & GFI & TLI & CFI & RMSEA \\
\hline & 16.684 & 15 & 1.112 & 0.99 & 0.99 & 0.99 & 0.02 \\
\hline
\end{tabular}

The regression coefficients for each path in the prediction model for teacher-student relationship quality are shown in Table 9. There are 13 paths reached significant level (Fig. 1).

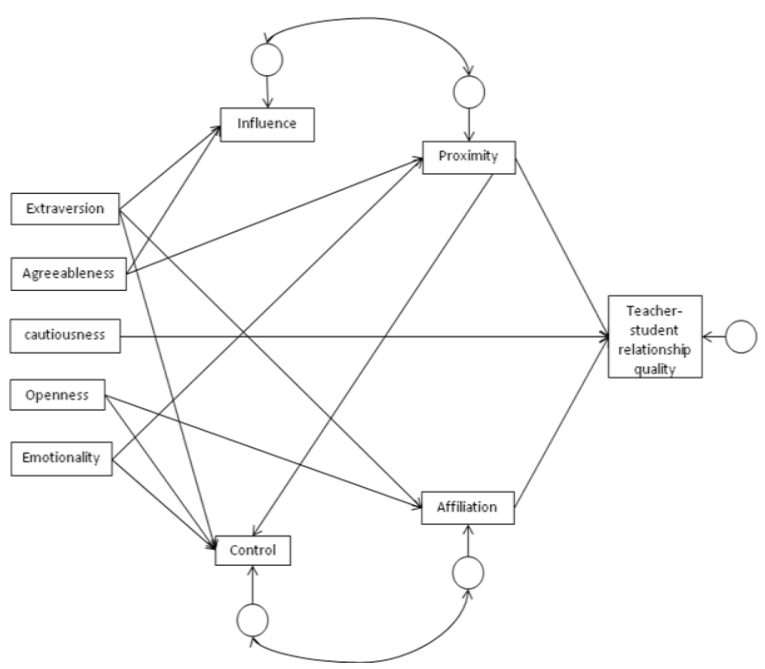

Fig. 1 The path model for teacher-student relationship quality

The path analysis results indicated that student's cautiousness, teacher proximity and student affiliation directly contribute to teacher-student relationship quality. The cumulative rate of interpretation was about $33 \%$. Although other student personality dimensions did not directly contribute to teacher-student relationship quality, they directly predict teacher-student interactions. Student personality accounts for $5.4 \%$ of the total variance of teacher influence, with student's extraversion and agreeableness positively predicting teacher influence. Student personality accounts for $17.8 \%$ of the total variance of teacher proximity, with student's agreeableness (positively) and emotionality (negatively) predicting teacher proximity. The variance of student control can be interpreted by student personality and teacher-initiated interaction together. The cumulative rate of interpretation is about $6.6 \%$, with student's extraversion (positively) and openness and emotionality (negatively) predicting student control. Student personality accounts for about $15.2 \%$ of the total variance of student affiliation, with extraversion (positively) and openness (negatively) predicting student affiliation.

The results of multiple regression analyses showed that only student's cautiousness directly predicts teacher-student relationship quality. And its prediction of teacher proximity is the only significant path to teacher-student interactions. Therefore, the only mediating effect can be considered is that student's cautiousness indirectly contributes to teacher-student relationship quality through teacher proximity. However, as shown by the path model, cautiousness directly predicts teacher-student relationship quality, but the prediction of teacher proximity became insignificant. In other words, the direct prediction effect is greater than the indirect effect between student's cautiousness and teacher-student relationship quality. Hence, the hypothesis of student personality indirectly influence teacher-student relationship through teacher-student interaction was not supported by the path model.

TABLE 9 Regression coefficients for the prediction model of teacherstudent relationship quality

\begin{tabular}{|c|c|c|c|c|c|c|}
\hline \multicolumn{2}{|c}{} & Timate & S.E. & C.R. & P \\
\hline Influence & $<---$ & $\mathrm{Ex}$ & 0.233 & 0.095 & 2.438 & 0.015 \\
\hline Affiliation & $<---$ & $\mathrm{Ex}$ & 0.242 & 0.077 & 3.124 & 0.002 \\
\hline Control & $<---$ & $\mathrm{Ex}$ & 0.166 & 0.080 & 2.068 & 0.039 \\
\hline Influence & $<---$ & $\mathrm{Ag}$ & 0.419 & 0.153 & 2.749 & 0.006 \\
\hline Proximity & $<---$ & $\mathrm{Ag}$ & 1.891 & 0.374 & 5.050 & $* * *$ \\
\hline TSR & $<---$ & $\mathrm{Ca}$ & 0.120 & 0.061 & 1.968 & 0.049 \\
\hline Affiliation & $<---$ & $\mathrm{Op}$ & -0.218 & 0.085 & -2.570 & 0.010 \\
\hline Control & $<---$ & $\mathrm{Op}$ & -0.189 & 0.085 & -2.223 & 0.026 \\
\hline Control & $<---$ & $\mathrm{Em}$ & -0.129 & 0.059 & -2.191 & 0.028 \\
\hline Proximity & $<---$ & Em & -0.457 & 0.166 & -2.758 & 0.006 \\
\hline TSR & $<---$ & Proximity & 0.069 & 0.014 & 4.840 & $* * *$ \\
\hline TSR & $<---$ & Affiliation & 0.477 & 0.042 & 11.382 & $* * *$ \\
\hline Control & $<---$ & Proximity & 0.058 & 0.026 & 2.244 & 0.025 \\
\hline
\end{tabular}

\section{Discussion and educational advices}

As shown in the path model, only student's cautiousness significantly predicts teacher-student relationship. The higher the cautiousness, the better the teacher-student relationship quality is. Some researches indicated that students with high cautiousness show higher learning initiative, persistency and better attention [12]. Cautiousness is positively correlated with individual's achievement and has great impact on student's 
learning behavior. Students with high cautiousness often are those who study hard and have better academic achievements. Middle schools are still under great amount of academic pressures in the Education system in China today. Student's academic achievement still is the main focus for most teachers, and it is also a key standard for evaluating student's performance. Therefore, those who have better academic achievements often become teacher's favorite students. Their relationships with teachers are generally better than those have less academic achievements.

This reminds us that most teachers tend to limit their evaluation of students to the student's academic achievements and often ignore other student qualities such as being extroversive, understanding, delicate sensitive, confident and with strong leadership, open and creative, or steady and rational. Those qualities also play important roles in students' development. A teacher's responsibility is not just imparting knowledge but more importantly educating people. As the guide and tutor for adolescent students during their critical transitional period in life, middle school teachers should be more open minded and more accepting for each student's uniqueness, be more giving and supportive, increase their confidence and promote their developments.

Furthermore, although the mediating effect of teacherstudent interactions between student personality and teacherstudent relationship was not found in this study, the path model did show different dimensions of student personality directly contribute to teacher-student interactions, which is noticeable and suggestive for educational practices. Firstly, student's high extraversion and agreeableness significantly predict higher teacher influence. And high agreeableness and low emotionality predict higher teacher proximity. These results indicated that students who are more outgoing, trusting and emotionally stable may trigger better teacher-initiated interactions, and vice versa.

Secondly, student's extraversion and openness directly contribute to student control and affiliation. Outgoing students tend to be more active, confident and close around their teachers. Students with high openness have broad interests, high pursuit of self-knowledge and independent opinions. On the other hand, they also have more personal independence of conducts. They are less concerned for the needs of others and not very sociable. These personality traits make them appear more cold and distant when they interact with their teachers and possibly cause more disagreements.

Thirdly, student's emotionality significantly predicts teacher proximity and student control. Students higher in emotionality report lower perceived teacher proximity, and show lower control when interact with teachers. They are quite sensitive, shy or irritable and easily get anxious. They often find it difficult to express themselves, and are easily ignored by others in social events. Sometimes they can be quite irritable, easily cause interpersonal conflicts and arguments which may lead to others' rejections. Therefore, they frequently concern whether their teachers are satisfied with them, and often avoid interactions with teachers in order to reduce anxiety. They are less active and confident during interactions.

To sum up, understanding how different student characteristics contribute to teacher-student interactions can help teachers enhance their sensitivity and flexibility when interacting with different students, and eventually improve teacher-student relationship quality.

\section{Conclusion}

This study examines the direct and indirect influences of student personality and teacher-student interactions on teacher-student relationship quality through path analyses. Main results include: (1) student's cautiousness positively predicts teacher-student relationship quality; (2) extraversion positively predicts teacher influence and student control and affiliation; agreeableness positively predicts teacher influence and proximity; openness negatively predicts student control and affiliation; emotionality negatively predicts teacher proximity and student control; (3) teacher proximity and student affiliation positively predict teacher-student relationship quality; (4) teacher proximity positively predicts student control; (5) the hypothesis that teacher-student interaction acts as a mediator between student personality and teacher-student relationship quality was not supported by the path model.

\section{References}

[1] N. Hughes, and O. Kwok, "Classroom engagement mediates the effect of teacher-student support on elementary students' peer acceptance: A prospective analysis," J. School Psychol., vol. 43, pp. 465-480, 2006.

[2] H. Birch, and W. Ladd, "The teacher-child relationship and children's early school adjustment," J. School Psychol., vol. 35, no. 1, pp. 61-79, 1997.

[3] F. Rice, and K. Dolgin, The adolescent: Development, relationships, and culture, Boston: Allyn and Bacon, 2005

[4] M. Gutman, and C. Midgley, "The role of protective factors in supporting the academic achievement of poor African American students during the middle school transition," J. Youth Adolesc., vol. 29, pp. 223-248, 2000.

[5] G. Reio, F. Marcus, and J. Sanders-Reio, "The contribution of student and instructor relationships and attachment style to school completion," J. Genet. Psychol., vol. 170, pp. 53-72, 2009.

[6] R. Wentzel, "Social relationships and motivation in middle school: The role of parents, teachers, and peers," J. Educ. Psychol., vol. 90, pp. 202209, 1998.

[7] H. Zhou, L. Niu, and H. Zou, "A Development study on Five-factor personality questionnaire for middle school students," Psychological Development and Education, vol. 16, no. 1, pp. 48-54, 2000.

[8] T. Wubbels, and M. Brekelmans, "Two decades of research on teacherstudent relationships in class," Int. J. Educ. Res., vol. 43, no.1-2, pp. 6-24, 2005.

[9] Y. Wang, "A study of the characteristics of the teacher-students relationship in primary school and its connection with student's development," Doctoral dissertation, Beijing: Beijing Normal University, 2002.

[10] J. Thijs, H. Koomen, D. Roorda, and J. Hagen, "Explaining teacherstudent interactions in early childhood: An interpersonal theoretical approach," J. Appl. Dev. Psychol., vol. 32, no. 1, pp. 34-43, 2011.

[11] Z. Wen, L. Zhang and J. Hou, "Testing and application of the mediating effects," Acta Psychologica Sinica, vol. 36, no. 5, pp. 614-620, 2004.

[12] H. Zou and C. Li, "Relationships of personality, learning behaviors, and teacher-student relationships in secondary school students," J. Beijing Normal University (Social Science), vol. 1, pp. 52-57, 2009. 